\title{
A model to predict the behaviour at part load operation of once-through heat recovery steam generators working with water at supercritical pressure
}

\author{
Antonio Rovira ${ }^{\mathrm{a}, *}$, Manuel Valdés ${ }^{\mathrm{b}}, \mathrm{M}^{\mathrm{a}}$ Dolores Durán ${ }^{\mathrm{c}}$ \\ ${ }^{a}$ E.T.S. Ingenieros Industriales de la UNED, Departamento de Ingeniería Energética, c/ Juan del Rosal n 12. 28040 Madrid, Spain \\ ${ }^{\mathrm{b}}$ E.T.S. Ingenieros Industriales de la U.P.M., Departamento de Ingeniería Energética y Fhidomecánica, c/ José Gutiérrez Abascal n 2.28006 Madrid, Spain \\ ${ }^{\complement}$ Facultad de Ingeniería de la UAEM, División de Ingeniería Mecánica, Cerro de Coatepec, C.U. 50110 Toluca, Mexico
}

\section{A R T I C L E I N F O}

\section{Keywords:}

Supercritical water

Heat recovery steam generator (HRSG)

Once-through boiler

Combined cycle gas turbine (CCGT),

exergetic losses

\begin{abstract}
A B S T R A C T
This paper describes a one-dimensional mathematical model that allows simulating the heat exchange in a steam generator working with water at supercritical pressure. The model has been developed in order to simulate the full and part load behaviour of heat recovery steam generators (HRSGs) of combined cycle gas turbine (CCGT) power plants. It takes into account the strong variation of some of the thermal and transport properties of fluids at supercritical pressure and discusses what parameters may be considered as constant along the heat exchanger.

On the one hand, the model is useful because going supercritical is considered a way to further improve the efficiency of CCGT power plants and, on the other hand, because part load operation is the most usual operation mode in power plants.
\end{abstract}

\section{Introduction}

Combined cycle gas turbines (CCGTs) power plants are one of the most efficient energy conversion systems. Owing to the good thermodynamic, economical and environmental performances that this kind of power plants may reach, nowadays they are undergoing widespread installation and the research in this field has notably increased.

A possible way to further improve the efficiency of these systems is to minimise the exergetic losses in the heat recovery steam generator (HRSG) by means of the use of water at supercritical pressure. The difference of temperatures in the heat exchange from a hot fluid to a cold one leads to exergetic losses. The exergetic losses imply a diminution of the steam turbine power and, consequently, a decrease in the CCGT efficiency $[1,2]$. The main advantage of working at supercritical pressure is that there is not a saturation temperature, unlike at subcritical pressure. Instead, the plain zone in the enthalpy-temperature diagram does not exist any more and any heat input towards the working fluid will increase its temperature, so the mentioned exergetic losses owing to the heat exchange decrease. This effect is observed in Fig. 1: Fig. 1a shows the thermal energy-temperature diagram of a subcritical triple pressure HRSG (with three drums at different pressures) while

\footnotetext{
* Corresponding author. Tel.: +34 913988224; fax: +34913987615.

E-mail addresses: rovira@ind.uned.es (A. Rovira), manuel.valdes@upm.es (M. Valdês), mduran@fi.uaemex.mx ( $\mathrm{M}^{\mathrm{a} D} \mathrm{D}$. Durán).
}

Fig. 1b shows a triple pressure HRSG with a supercritical high pressure level. Such behaviour could remain at part load operation if the exhaust temperature of the gas turbine is controlled (for example, using compressors with variable inlet guide vanes) as the drop of temperature and pressure of the steam is lower than using other regulation systems $[3,4]$. Other advantages are the simplicity of the HRSG - once-through HRSGs can be employed - which should lead to cheaper designs [5,6] and faster start-up times [7].

Owing to these reasons and to the advances in experimental research - for example, Dechamps and Galopin [8] and Dumont and Heyen [9] - working with water at supercritical pressure is near to be technically and economically feasible in CCGT power plants (Najjar [5], Dechamps [10] and Galopin [11]) as well as in coal fired power plants (Beér [12]).

The simulation of the heat exchange in the HRSG when the power plant operates at part load conditions is interesting in order to predict the power plant performances when the demanded power is lower than the reached at full load operation or when the ambient conditions change. Part load calculations are usually much more time-consuming than the design condition (full load operation) ones. For example, the calculation time of a subcritical CCGT from full load until a load of $50 \%$ may be over one thousand times greater than that spent in calculating the design condition. Due to the nature of the water at supercritical pressure, which is introduced in Section 2, the time of calculation of a HRSG working with water at supercritical pressure would become even larger. Since this point of view, a complete three-dimensional model that 


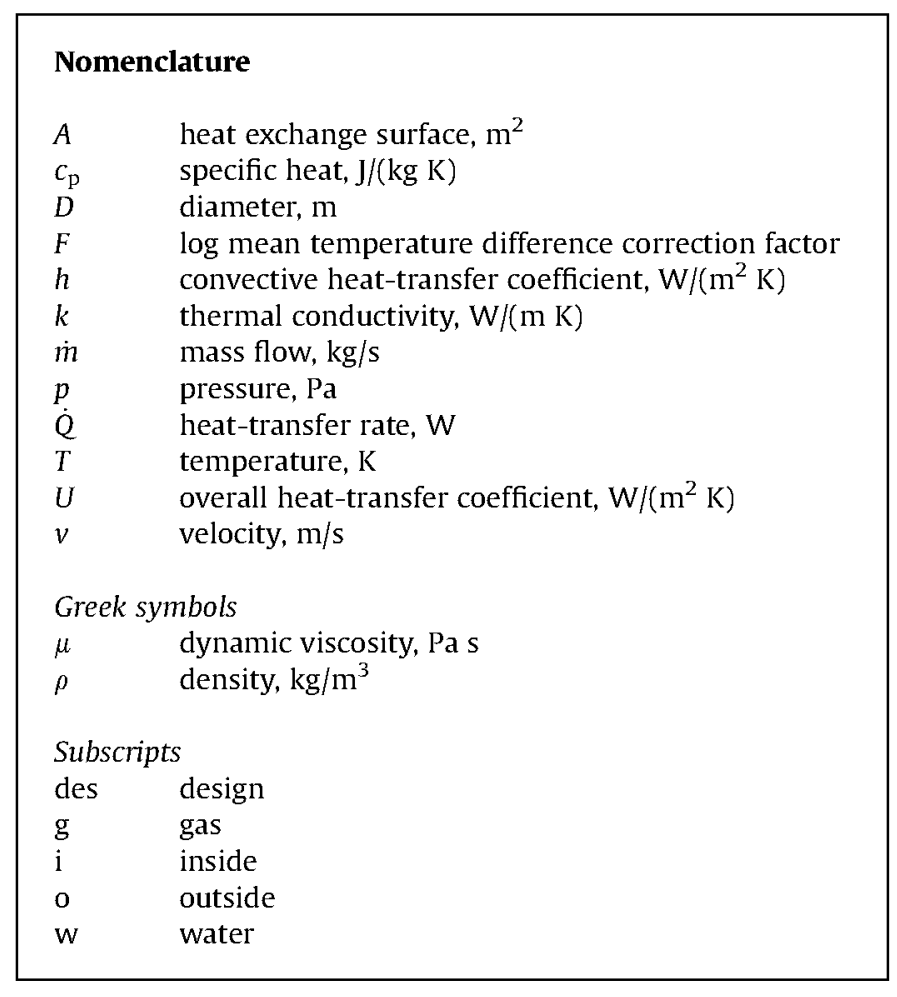

simulates the heat exchangers without any simplification is not advisable if the purpose is, for example, systematically analysing wide part load ranges or performing annual simulations of CCGT.

The objective of this paper is to propose a simplified mathematical model, similar to the already existent one-dimensional subcritical ones (Valdés et al., [13]), that allows simulating the heat exchange in once-through HRSGs working with water at supercritical pressure in a broad load range of the CCGT with enough accuracy and calculation times comparable to the subcritical model ones.

Finally, the model - that has been used in Rovira [4] - is validated with experimental data obtained from ref. [8].

\section{Heat transfer to water at supercritical pressure}

The behaviour of fluids at supercritical pressure is mainly characterised by a strong variation of their thermal and transport properties $^{1}$ with the temperature. This behaviour makes impossible to assume that the properties are constant in the mathematical models, unlike what is usual in the subcritical mathematical models. For that reason, numerical methods are required instead of the usual symbolic solutions.

Furthermore, the strong variation of the fluid properties near the pseudocritical condition ${ }^{2}$ causes the phenomena called 'heattransfer enhancement' and 'heat-transfer deterioration', whose influence on the HRSG heat transfer has to be considered.

The expressions that describe the heat exchange of the different HRSG heat exchangers (economisers, evaporators and superheaters) are shown in the following sections. The well known subcritical models will be adapted to simulate the heat exchange towards water at supercritical pressure in the cases of full load operation and part load operation of the power plant.

\footnotetext{
${ }^{1}$ The IAPWS Industrial Formulation 1997 for the Thermodynamic Properties of Water and Steam [14] has been used.

${ }^{2}$ The pseudocritical condition is reached when the specific heat has a maximum value. That condition may be considered as the frontier between the liquid and vapour state.
}

\subsection{Heat exchange equations in $H R S G$}

Two equations are needed to predict the behaviour of heat exchangers working with fluids at subcritical pressure: the energy balance and a heat exchange equation. When the HRSG of a CCGT power plant is analysed at the design condition, the energy balance (together with the knowledge of a given number of design parameters) provides the value of the design temperatures in every point of the HRSG (Valdes et al. [13] and [15]). If a counter-flow exchanger is used, the heat exchange equation allows calculating the $U A$ product (product of the overall heat-transfer coefficient $U$ and the exchange surface $A$ ) by means of the logarithmic mean temperature difference of the exchanger ${ }^{3}$ :

$$
\dot{\mathrm{Q}}=U A \cdot \frac{\left(T_{\mathrm{g} \text { in }}-T_{\mathrm{W} \text { out }}\right)-\left(T_{\mathrm{g} \text { out }}-T_{\mathrm{W} \text { in }}\right)}{\ln \left(\frac{T_{\mathrm{g} \text { in }}-T_{\mathrm{W} \text { out }}}{T_{\mathrm{g} \text { out }}-T_{\mathrm{W} \text { in }}}\right)}
$$

The $U A$ product is the base to predict later the performance of the heat exchanger at part load operation.

The expressions of the mathematical model that describe the heat exchanger working with a fluid at supercritical pressure are similar to the subcritical case. Nevertheless, they should take into account that most of the properties, for example the specific heat, cannot be assumed as constant - with the exception of the overall heat-transfer coefficient $(U)$ in a first approach, as it will be explained in Section 2.2. In such a case, equation (1) is not valid any more. To avoid this problem, when a flow works at supercritical pressure the following methodology could be used:

\subsubsection{Full load operation}

The equations that govern the heat exchange (Fig. 2), again in the case of a counter-flow heat exchanger ${ }^{3}$ applied to the design point are:

$$
\left\{\begin{array}{l}
\mathrm{d} \dot{Q}=-\dot{m}_{\mathrm{g} \text { des }} \cdot C_{\mathrm{P}} \cdot \mathrm{d} T_{\mathrm{g}} \\
\mathrm{d} \dot{Q}=-\dot{m}_{\mathrm{w} \text { des }} \cdot C_{\mathrm{P}} \cdot \mathrm{d} T_{\mathrm{w}} \\
\mathrm{d} \dot{Q}=U_{\mathrm{des}} \cdot \mathrm{d} A \cdot\left(T_{\mathrm{g}}-T_{\mathrm{w}}\right)=(U A)_{\mathrm{des}} \cdot\left(T_{\mathrm{g}}-T_{\mathrm{w}}\right) \cdot \mathrm{d} x
\end{array}\right.
$$

where $x$ varies between 0 and 1 and represents a dimensionless length of the exchanger.

Combining the first and the second equations, the following energy balance is obtained:

$$
\begin{gathered}
\int_{T_{\mathrm{g} \text { in des }}}^{T_{\mathrm{g}}} \dot{m}_{\mathrm{g} \text { des }} \cdot c_{\mathrm{P} \mathrm{g}} \cdot \mathrm{d} T_{\mathrm{g}}=\int_{T_{\mathrm{w} \text { out des }}}^{T_{\mathrm{w}}} \dot{m}_{\mathrm{W} \text { des }} \cdot c_{\mathrm{P} \mathrm{w}} \cdot \mathrm{d} T_{\mathrm{W}} \\
T_{\mathrm{g}}=T_{\mathrm{g} \text { in des }}+\int_{T_{\mathrm{w} \text { out des }}}^{T_{\mathrm{w}}} \frac{\dot{m}_{\mathrm{w} \text { des }} \cdot c_{\mathrm{P} \mathrm{w}}}{\dot{m}_{\mathrm{g} \text { des }} \cdot c_{\mathrm{P} \mathrm{g}}} \cdot \mathrm{d} T_{\mathrm{W}}
\end{gathered}
$$

On the other hand, combining the last two equations of (2):

$\mathrm{d} x=\frac{-\dot{m}_{\mathrm{w} \mathrm{des}} \cdot C_{\mathrm{P}}}{U A_{\mathrm{des}} \cdot\left(T_{\mathrm{g}}-T_{\mathrm{w}}\right)} \cdot \mathrm{d} T_{\mathrm{w}}$

Equation (5) may be integrated assuming $U$ as constant along the exchanger (see Section 2.2):

\footnotetext{
${ }^{3}$ In this section, the mathematical model is developed for a counter-flow heat exchanger. It may be also developed for any other one using the correction factor.
} 

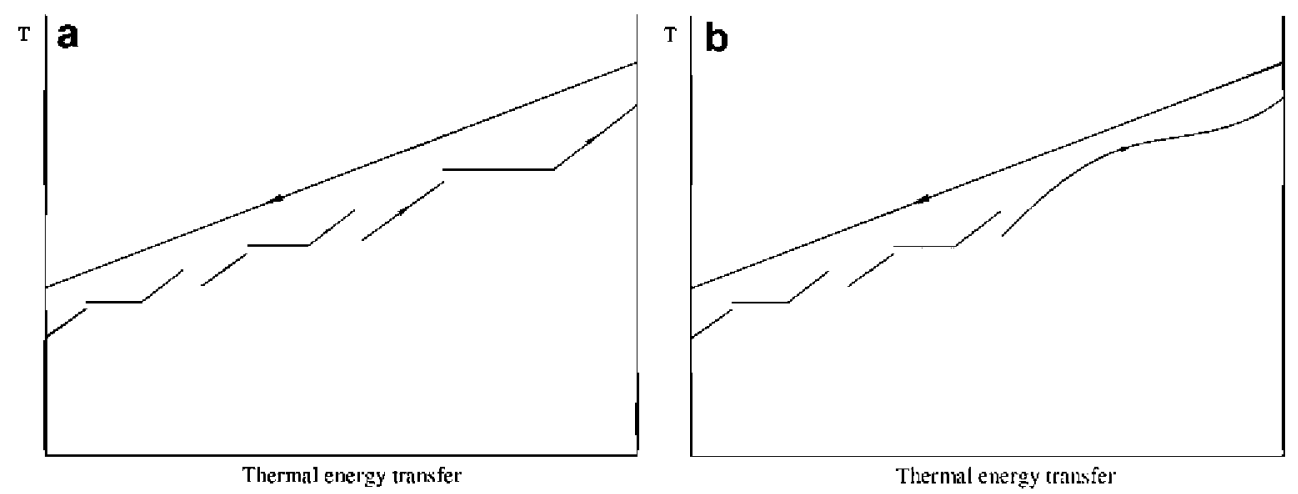

Fig. 1. Thermal energy-temperature diagram of a subcritical HRSG (a) and a supercritical HRSG (b).

$\mathbf{1}=-\frac{\dot{m}_{\mathrm{w} \text { des }}}{U A_{\mathrm{des}}} \cdot \int_{T_{\mathrm{w} \text { out des }}}^{T_{\mathrm{w} \text { in }}} \frac{c_{\mathrm{P} \mathrm{w}}}{\left(T_{\mathrm{g}}-T_{\mathrm{w}}\right)} \cdot \mathrm{d} T_{\mathrm{w}}$

$U A_{\text {des }}=\dot{m}_{\mathrm{w} \text { des }} \cdot \int_{T_{\mathrm{w} \text { in }}}^{T_{\mathrm{w}} \text { out des }} \frac{c_{\mathrm{P} \mathrm{w}}}{\left(T_{\mathrm{g}}-T_{\mathrm{w}}\right)} \cdot \mathrm{d} T_{\mathrm{w}}$

For heat exchangers different from counter-flow ones, the equation (7) should be corrected with a factor $(F)$ which is less than 1 :

$F_{\mathrm{des}} \cdot U A_{\mathrm{des}}=\dot{m}_{\mathrm{w} \text { des }} \cdot \int_{T_{\mathrm{w} \text { in }}}^{T_{\mathrm{w} \text { out des }}} \frac{C_{\mathrm{P} \mathrm{w}}}{\left(T_{\mathrm{g}}-T_{\mathrm{w}}\right)} \cdot \mathrm{d} T_{\mathrm{w}}$

Equation (8) may be numerically integrated at the design point of the power plant taking into account equation (4) (to calculate the gas temperature) and the value of $c_{\mathrm{pw}}$, which varies at each step of the numerical integration. Therefore the $F_{\text {des }} \cdot U A_{\text {des }}$ product is calculated.

Equations (4) and (8) are the energy balance and the heat exchange expressions respectively, and the F.UA product may be obtained.

\subsubsection{Part load operation}

Once the $F \cdot U A$ product is obtained at the design point, it may be calculated at any other part load of the CCGT as it will be shown in Section 2.2. The calculation of any two variables, for example $T_{g}$ out and $T_{\mathrm{w}}$ in, may be done assuming that the others, $T_{\mathrm{g}}$ in, $T_{\mathrm{W} \text { out }}, \dot{m}_{\mathrm{W}}$ and $\dot{m}_{g}$, are known and using the corresponding $U A$ product in the part load operation point:

$$
\begin{aligned}
d\left(T_{\mathrm{g}}-T_{\mathrm{W}}\right) & =\mathrm{d} T_{\mathrm{g}}-\mathrm{d} T_{\mathrm{W}} \\
& =-\left(\frac{1}{c_{\mathrm{P} \mathrm{g}} \cdot \dot{m}_{\mathrm{g}}}-\frac{1}{c_{\mathrm{P} \mathrm{w}} \cdot \dot{m}_{\mathrm{w}}}\right) \cdot \mathrm{d} \dot{Q}=-r \cdot \mathrm{d} \dot{Q}
\end{aligned}
$$

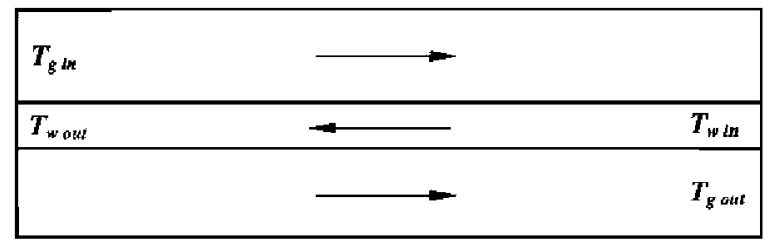

Fig. 2. Schematic of a counter-flow heat exchanger.
$d\left(T_{\mathrm{g}}-T_{\mathrm{W}}\right)=r \cdot \dot{m}_{\mathrm{W}} \cdot c_{\mathrm{PW}} \cdot \mathrm{d} T_{\mathrm{W}}$

where expressions (9) and (10) derive from equation (2). Integrating equation (10):

$\int_{\left(T_{\mathrm{g} \text { in }}-T_{\mathrm{W} \text { out }}\right)}^{\left(T_{\mathrm{g}}-T_{\mathrm{W}}\right)} d\left(T_{g}-T_{w}\right)=\dot{m}_{\mathrm{W}} \cdot \int_{T_{\mathrm{W} \text { out }}}^{T_{\mathrm{w}}} r \cdot c_{\mathrm{P} \mathrm{w}} \cdot \mathrm{d} T_{\mathrm{W}}$

$\left(T_{\mathrm{g}}-T_{\mathrm{W}}\right)_{T_{\mathrm{w}}}=\left(T_{\mathrm{g} \text { in }}-T_{\mathrm{W} \text { out }}\right)+\dot{m}_{\mathrm{W}} \cdot \int_{T_{\mathrm{w} \text { out }}}^{T_{\mathrm{w}}} r \cdot c_{\mathrm{P} \mathrm{w}} \cdot \mathrm{d} T_{\mathrm{W}}$

The integral may be numerically solved decreasing $T_{\mathrm{W}}$ at each step of the process. Thus, the value of $\left(T_{\mathrm{g}}-T_{\mathrm{W}}\right)$ is known for each intermediate value of $T_{\mathrm{W}}$.

At the same time, considering equation (5) and using its respective $U A$ value and the correction factor $F$ :

$x=-\frac{\dot{m}_{\mathrm{W}}}{F \cdot U A} \cdot \int_{T_{\mathrm{w} \text { out }}}^{T_{\mathrm{w}}} \frac{C_{\mathrm{P} \mathrm{w}}}{\left(T_{\mathrm{g}}-T_{\mathrm{w}}\right)} \cdot \mathrm{d} T_{\mathrm{W}}$

With equations (12) and (13) it is possible to calculate the value of $x$ for each $T_{\mathrm{W}}$. The numerical integrations conclude when $x=1$ and then, $T_{\mathrm{g} \text { out }}$ and $T_{\mathrm{W}}$ in are the values corresponding to this final step of the process.

Equations (12) and (13) are again the energy balance and heattransfer equations.

\subsection{Calculation of the overall heat-transfer coefficient of} supercritical fluids at part load operation

In order to evaluate the expressions (12) and (13), the knowledge of the F.UA product at any part load operation is needed. To this end it is enough to find the $(F \cdot U) /\left(F_{\text {des }} \cdot U_{\text {des }}\right)$ ratio since the previously calculated heat exchange surface $A$ is constant.

As it is known, the overall heat transfer coefficient is defined as the resistance that exists in the heat exchange between two different fluids. In the particular case of a heat exchanger in which the fluids flow inside and outside a tube, $U$ may be calculated [16]:

$U=\frac{1}{\frac{1}{h_{\mathrm{g}}}+\frac{r_{\mathrm{o}} \cdot \ln \left(r_{\mathrm{o}} / r_{\mathrm{i}}\right)}{k}+\frac{r_{\mathrm{o}}}{r_{\mathrm{i}} \cdot h_{\mathrm{w}}}}$

where $r_{0}$ and $r_{\mathrm{i}}$ are, respectively, the outside and inside radius of the tube, $k$ is its thermal conductivity and $h_{\mathrm{g}}$ and $h_{\mathrm{w}}$ are the gas and the water-side convective heat-transfer coefficients. Typical values for the terms in subcritical HRSGs of CCGT are shown in Table 1. In this 
Table 1

Typical values of the terms of equation (13) in HRSGs ${ }^{\mathrm{a}}$.

\begin{tabular}{llll}
\hline & $h_{\mathrm{g}}\left[\mathrm{W} /\left(\mathrm{m}^{2} \mathrm{~K}\right)\right]$ & $k / r_{\mathrm{o}} \cdot \ln \left(r_{\mathrm{o}} / r_{\mathrm{i}}\right)\left[\mathrm{W} /\left(\mathrm{m}^{2} \mathrm{~K}\right)\right]$ & $r_{\mathrm{i}} \cdot h_{\mathrm{W}} / r_{\mathrm{o}}\left[\mathrm{W} /\left(\mathrm{m}^{2} \mathrm{~K}\right)\right]$ \\
\hline Economizers & $50-100$ & $2000-6000$ & $2000-20000$ \\
Evaporators & $\sim 50$ & $5000-10000$ & $2000-20000$ \\
Superheaters & $50-100$ & $2000-10000$ & $1000-5000$ \\
\hline
\end{tabular}

${ }^{a}$ Usual geometrical data were obtained from ref. [17]. Heat exchanger designs and convective heat-transfer coefficients were calculated as explained in ref. [18]. Thermal conductivity of the materials was extracted from ref. [16].

table it may be observed that, especially in economisers and evaporators, the term corresponding to the gas side $\left(h_{g}\right)$ is much lower than the thermal conductivity and the water-side terms ( $k$ and $h_{\mathrm{w}}$ ). Therefore, in economisers and evaporators expression (14) may be simplified:

$U \approx \frac{1}{1 / h_{\mathrm{g}}}=h_{\mathrm{g}}$

In flows at subcritical pressure, the convective heat-transfer coefficients $(h)$ are usually calculated by means of empirical dimensionless relations. For flows inside a tube, a commonly used expression is the Dittus-Boelter equation [19]:

$N u=0.023 \cdot \operatorname{Re}^{0.8} \cdot \operatorname{Pr}^{0.4}$

where $N u$ is the Nusselt, Re the Reynolds (both based on the hydraulic diameter of the tube) and $P r$ the Prandtl number. All of them, at subcritical pressures, are evaluated at the mean bulk temperature.

At supercritical pressure, the heat-transfer coefficient may deviate from the Dittus-Boelter equation near the pseudocritical condition, as reported by Petuhkov [20]. This phenomenon is called heat-transfer enhancement or deterioration (as it increases or decreases the coefficient respectively) and it should be taken into account to correct the Dittus-Boelter equation [21-24]. Although these phenomena might be important in some applications, in this study they has been neglected, mainly because the heat-transfer coefficient of the water is much higher than the gas one (as it is shown in the Appendix). In such a situation, the gas establishes the strongest resistance to the heat exchange and governs the heat exchange. Also, the nearby of the pseudocritical point is only reached in a very small region of the heat exchange domain.

For the flows outside of the tubes (gas side in the HRSG), the expression proposed by Shmith [25] and used in HRSG by Weir [26] may be used:

$N u=a \cdot \operatorname{Re}^{m} \cdot \operatorname{Pr}^{n} \cdot \Phi_{\mathrm{a}}^{1-m}$

where $\Phi_{a}$ is a parameter that depends on the geometry of the exchanger (it takes into account the number and size of the fins and the bank tube geometry). For a heat recovery boiler, $a, m$ and $n$ are respectively $0.3,0.625$ and $1 / 3$ (Weir [26]). Nu and Re are based on the hydraulic diameter (four times the cross sectional area divided by the wetted perimeter) and $\mathrm{Nu}, \mathrm{Re}$ and $\mathrm{Pr}$ are evaluated at the mean bulk temperature.

Once the convective heat-transfer coefficient has been calculated at the design condition, $U$ could be obtained at every part load condition using the following equation:

$$
\begin{aligned}
U= & \frac{1}{\frac{1}{h_{\mathrm{g}}}+\frac{r_{\mathrm{o}} \cdot \ln \left(r_{\mathrm{o}} / r_{\mathrm{i}}\right)}{k}+\frac{r_{\mathrm{o}}}{r_{\mathrm{i}} \cdot h_{\mathrm{w}}}} \\
= & \frac{1}{\frac{1}{h_{\mathrm{g} \text { des }} \cdot \frac{h_{\mathrm{g}}}{h_{\mathrm{g} \text { des }}}}+\frac{r_{\mathrm{o}} \cdot \ln \left(r_{\mathrm{o}} / r_{\mathrm{i}}\right)}{k}+\frac{r_{\mathrm{o}}}{r_{\mathrm{i}} \cdot h_{\mathrm{w} \text { des }} \cdot \frac{h_{\mathrm{w}}}{h_{\mathrm{w} \text { des }}}}}
\end{aligned}
$$

The subscript des makes reference to the nominal or design condition. The relations $h_{\mathrm{g}} / h_{\mathrm{g}}$ des and $h_{\mathrm{w}} / h_{\mathrm{w} \text { des }}$ may be calculated as it is indicated in Section 2.3.

For economisers and evaporators expression (18) may be simplified as follows:

$U \approx h_{\mathrm{g}}=h_{\mathrm{g} \text { des }} \cdot \frac{h_{\mathrm{g}}}{h_{\mathrm{g} \text { des }}}$

and the F.UA product may be calculated:

$F \cdot U A=F_{\mathrm{des}} \cdot U A_{\mathrm{des}} \cdot \frac{F \cdot U}{F_{\mathrm{des}} \cdot U_{\mathrm{des}}}=F_{\mathrm{des}} \cdot U A_{\mathrm{des}} \cdot \frac{F}{F_{\mathrm{des}}} \cdot \frac{h_{\mathrm{g}}}{h_{\mathrm{g} \text { des }}}$

The coefficients $h_{\mathrm{g} \text { des }}$ and $h_{\mathrm{W} \text { des }}$ depend on the geometry of the heat exchanger. Thus, equations (18) and (19) have the disadvantage of requiring the knowledge of the geometric design of the exchanger. Equation (20) suggests that the heat exchange is mainly governed by the gas flow. For that reason $U$ may be assumed as constant along the heat exchanger, which should be taken into account when integrating equation (5).

The influence of the $F / F_{\text {des }}$ ratio is assessed in Section 3 by means of a sensitivity analysis.

\subsection{Calculation of the convective heat-transfer coefficient of flows at part load operation}

The convective heat-transfer coefficient $(h)$ is a variable that depends on the temperature, the pressure, the velocity of the stream and the geometry of the exchanger. As it was said before, for a stream flowing through the outside of a finned tube the equation (17) may be used. Replacing the non-dimensional numbers by their definitions:

$\left(\frac{h_{\mathrm{g}} D_{\mathrm{g}}}{k_{\mathrm{g}}}=a \cdot\left(\frac{\rho_{\mathrm{g}} \nu_{\mathrm{g}} D_{\mathrm{g}}}{\mu_{\mathrm{g}}}\right)^{m}\left(\frac{\mu_{\mathrm{g}} c_{\mathrm{pg}}}{k_{\mathrm{g}}}\right)^{n} \cdot \Phi_{\mathrm{a}}^{1-m}\right)$

where $D_{\mathrm{g}}$ is the characteristic length of the flow. Solving for $h_{\mathrm{g}}$ :

$h_{\mathrm{g}}=\frac{a}{D_{\mathrm{g}}} \cdot k_{\mathrm{g}} \cdot \frac{\rho_{\mathrm{g}}^{m} v_{\mathrm{g}}^{m} D_{\mathrm{g}}^{m}}{\mu_{\mathrm{g}}^{m}} \cdot \frac{\mu_{\mathrm{g}}^{n} c_{\mathrm{pg}}^{n}}{k_{\mathrm{g}}^{\mathrm{n}}} \cdot \Phi_{\mathrm{a}}^{1-m}$

Reorganising the terms and taking into account that $\dot{m}_{\mathrm{g}}=\rho_{\mathrm{g}} \cdot v_{\mathrm{g}} \cdot A_{\mathrm{g}}$ (where $A_{\mathrm{g}}$ is the cross sectional surface):

$$
\begin{aligned}
h_{\mathrm{g}} & =\frac{a \cdot D_{\mathrm{g}}^{m-1}}{A_{\mathrm{g}}^{m}} \cdot \frac{\mu_{\mathrm{g}}^{n} c_{\mathrm{pg}}^{n}}{k_{\mathrm{g}}^{n}} \cdot \frac{k_{\mathrm{g}}}{\mu_{\mathrm{g}}^{m}} \cdot \dot{m}_{\mathrm{g}}^{m} \cdot \Phi_{\mathrm{a}}^{1-m} \\
& =\frac{a \cdot D_{\mathrm{g}}^{m-1}}{A_{\mathrm{g}}^{m}} \cdot \frac{c_{\mathrm{pg}}^{n}}{\mu_{\mathrm{g}}^{m-n} k_{\mathrm{g}}^{n-1}} \cdot \dot{m}_{\mathrm{g}}^{m} \cdot \Phi_{\mathrm{a}}^{1-m}
\end{aligned}
$$

Rapun [27] and Duran [28] expand and reorganise expression (23) as below in order to express the convective heat-transfer coefficient as a function of three terms. One of them is constant and only depends of the geometry $(T)$, the second variable depends on the thermal state of the fluid $(\beta)$ and the last one depends on the mass flow of the stream:

$$
\begin{aligned}
h_{\mathrm{g}} & =\left(\frac{0.3 \cdot D_{\mathrm{g}}^{0.625-1}}{A_{\mathrm{g}}^{0.625} \cdot \Phi_{\mathrm{a}}^{0.625-1}}\right) \cdot\left(\frac{c_{\mathrm{pg}}^{0.625}}{\operatorname{Pr}_{\mathrm{g}}^{0.625-1 / 3} \cdot k_{\mathrm{g}}^{0.625-1}}\right) \cdot \dot{m}_{\mathrm{g}}^{0.625} \\
& =\Gamma_{\mathrm{g}} \cdot \beta_{\mathrm{g}} \cdot \dot{m}_{\mathrm{g}}^{0.625}
\end{aligned}
$$

where the $a, m$ and $n$ coefficient have been replaced by the values proposed in ref. [26]. 


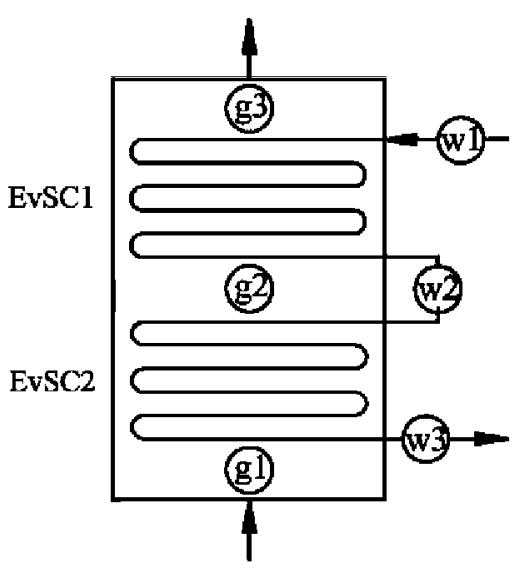

Fig. 3. Once-through HRSG.

Finally, the expression for $h_{\mathrm{g}} / h_{\mathrm{g}}$ des is obtained:

$$
\begin{aligned}
\frac{h_{\mathrm{g}}}{h_{\mathrm{gdes}}}=\frac{\Gamma_{\mathrm{g}} \cdot \beta_{\mathrm{g}} \cdot \dot{m}_{\mathrm{g}}^{0.625}}{\Gamma_{\mathrm{g}} \cdot \beta_{\mathrm{gdes}} \cdot \dot{m}_{\mathrm{gdes}}^{0.625}}= & \left(\frac{k_{\mathrm{g}}}{k_{\mathrm{gdes}}}\right)^{0.375}\left(\frac{c_{\mathrm{Pg}}}{c_{\text {Pgdes }}}\right)^{0.625} \\
& \left(\frac{\operatorname{Pr}_{\mathrm{gdes}}}{\operatorname{Pr}_{\mathrm{g}}}\right)^{0.625-1 / 3}\left(\frac{\dot{m}_{\mathrm{g}}}{\dot{m}_{\mathrm{gdes}}}\right)^{0.625}
\end{aligned}
$$

The above expression depends on the thermodynamic state and the gas mass flow but not on the geometric design of the exchanger. Therefore, the disadvantage that arose in equation (18) disappears in equation (20).

\section{Validation of the model}

In order to validate the proposed model, data from an experimental HRSG [8] are used. The schematic of the HRSG is shown in Fig. 3 and its main geometric data are shown in Table 2. It has two heat exchangers: the first one (EvSC1) works as an economizer and an evaporator and the second one (EvSC2) works as a superheater. The gas flows outside the tubes of the heat exchangers.

In the cited work, the performance of the HRSG is provided in two different operating conditions. These conditions, shown in Table 3, differ in the mass flow of the gas, but the inlet gas temperature $\left(T_{\mathrm{g} 1}\right)$, the feed water temperature $\left(T_{\mathrm{w} 1}\right)$, the steam temperature $\left(T_{\mathrm{w} 3}\right)$ and the pressure are the same in both cases. They were the input data of the simulation, so the variables to be validated were the gas outlet temperature of each exchanger $\left(T_{\mathrm{g} 2}\right.$ and $\left.T_{\mathrm{g} 3}\right)$, the intermediate water temperature $\left(\mathrm{T}_{\mathrm{w} 2}\right)$ and the steam mass flow.

It has been assumed that condition 1 of Table 3 corresponds to the full load condition of the experimental HRSG. Hence, an HRSG similar to the experimental one was simulated and, afterwards, the

Table 2

Main heat exchange surface design data (extracted from ref. [8]).

\begin{tabular}{lll}
\hline Heat exchanger & Econo-evap & Superheater \\
\hline Tube diameter $(\mathrm{mm})$ & 25 & 26.5 \\
Tube thickness $(\mathrm{mm})$ & 2.9 & 4.2 \\
Number of rows & 18 & 6 \\
Useful length $(\mathrm{m})$ & 6 & 6 \\
Fins per meter $\left(\mathrm{m}^{-1}\right)$ & 200 & 200 \\
Fin diameter $(\mathrm{mm})$ & 49 & 49 \\
Tube layout & Staggered & Staggered \\
Transverse pitch $(\mathrm{mm})$ & 83 & 83 \\
Longitudinal pitch $(\mathrm{mm})$ & 73 & 73 \\
\hline
\end{tabular}

Table 3

Experimental data and model estimation for the HRSG variables.

\begin{tabular}{lccccc}
\hline \multirow{2}{*}{ Variable } & \multicolumn{2}{l}{ Condition 1} & & \multicolumn{2}{c}{ Condition 2} \\
\cline { 2 - 3 } \cline { 5 - 6 } & Real & Simulation & & Real & Simulation \\
\hline$\dot{m}_{\mathrm{g}}(\mathrm{kg} / \mathrm{s})$ & 22.2 & 22.1 & & 14.7 & 14.8 \\
$\dot{m}_{\mathrm{w}}(\mathrm{kg} / \mathrm{s})$ & 3.83 & 3.85 & & 2.6 & 2.6 \\
$T_{\mathrm{g} 1}(\mathrm{~K})$ & 923 & 923 & & 923 & 923 \\
$T_{\mathrm{g} 2}(\mathrm{~K})$ & 822 & 823.7 & & 808 & 810.0 \\
$T_{\mathrm{g} 3}(\mathrm{~K})$ & 493 & 488.2 & & 479 & 474.6 \\
$T_{\mathrm{w} 3}(\mathrm{~K})$ & 793 & 793 & & 793 & 793 \\
$T_{\mathrm{w} 2}(\mathrm{~K})$ & 665 & 667.1 & & 667 & 662.8 \\
$T_{\mathrm{w} 1}(\mathrm{~K})$ & 378 & 378 & & 378 & 378 \\
$\mathrm{p}(\mathrm{bar})$ & 240 & 240 & & 240 & 240 \\
$F \cdot U A_{\mathrm{EvSC} 1}(\mathrm{~kW} / \mathrm{K})$ & 17.4 & 16.9 & & 12.1 & 12.7 \\
$F \cdot U A_{\mathrm{EvSC} 2}(\mathrm{~kW} / \mathrm{K})$ & 102.9 & 110.2 & & 91.2 & 84.5 \\
\hline
\end{tabular}

$(F \cdot U A)_{\text {des }}$ product of their heat exchangers were calculated as described in Section 2.1.1. Once the $(F \cdot U A)_{\text {des }}$ products were obtained, the value of the air mass flow was gradually reduced in the simulation program until condition 2 was reached. As said before, $T_{\mathrm{g} 1}, T_{\mathrm{w} 1}, T_{\mathrm{w} 3}$ and the pressure remained constant and $T_{\mathrm{g} 2}, T_{\mathrm{g} 3}$. $\mathrm{T}_{\mathrm{W} 2}$ and the steam mass flow were the results of the simulation, which followed the steps described in Section 2.1.2.

Table 3 compares the results obtained in the mentioned work together with those obtained in the simulation. It can be observed that the results obtained using the proposed model for $\dot{m}_{\mathrm{w}}, T_{\mathrm{g} 2}, T_{\mathrm{g} 3}$ and $T_{\mathrm{w} 2}$ fit well with the experimental values, and that the trends obtained predict accurately the actual HRSG performance. The value of the F.UA product of the heat exchangers are also compared, both for the real and the simulated HRSG. They were obtained using equation (8). Differences are below $10 \%$ for both exchangers at the two conditions. It should be noted that the correction factor F may affect the results at condition 2 because their values may vary from the full load condition to the part load one.

In Table 3, the results have been obtained for a value of $F / F_{\text {des }}$ of 1 in equation (20). When the load of a CCGT decreases, the generation of steam in the HRSG also does. Therefore, at part load operation the HRSG is oversized and its efficiency slightly increases. For that reason, the heat transfer along the exchangers should vary and the ratio $F / F_{\text {des }}$ may differ from 1 [16]. Actually, the factor $F$ takes a value between that corresponding to a cross-flow exchanger and 1 , corresponding to a counter-flow exchanger. The greater the amount of bank of tubes is, the higher the value of $F$ is, and its value is close to 1 for well-designed exchangers [29]. Since HRSG consists on several banks of tubes, $F / F_{\text {des }}$ should not vary at a large extent.

In order to quantify the uncertainty that this ratio introduce, sensitivity analysis was done. Table 4 shows how the steam production and the temperatures vary when the ratio $F / F_{\text {des }}$ is altered. The other parameters do not vary. Calculations were done only for condition 2 because condition 1 corresponds to the design point, and the results are shown as percentage changes. When $F / F_{\text {des }}$ is modified a $20 \%$ toward higher or lower values, variations of the results are below $4.5 \%$. If $F / F_{\text {des }}$ is modified a $10 \%$, the variations are even below $2 \%$. Lower variations of $F / F_{\text {des }}$, expected in large HRSGs, lead to small uncertainties.

Table 4

\begin{tabular}{|c|c|c|c|c|c|}
\hline$F / F_{\text {des }}$ & 0.8 & 0.9 & 1 & 1.1 & 1.2 \\
\hline$\Delta \dot{m}_{w}(\%)$ & -4.38 & -1.87 & 0.00 & 1.70 & 3.30 \\
\hline$\Delta \mathrm{T}_{\mathrm{g} 2}(\%)$ & 2.37 & 0.87 & 0.00 & -1.48 & -2.91 \\
\hline$\Delta \mathrm{T}_{\mathrm{g} 3}(\%)$ & 4.14 & 1.83 & 0.00 & -1.72 & -3.32 \\
\hline$\Delta \mathrm{T}_{\mathrm{w} 2}(\%)$ & 1.03 & 0.30 & 0.00 & -0.47 & -0.80 \\
\hline
\end{tabular}

Sensitivity analysis of $F / F_{\text {des }}$. 


\section{Conclusions}

A methodology to simulate the heat exchange process between a gas and a fluid at supercritical pressure has been proposed. It takes into account that the UA product cannot be calculated using the logarithmic mean temperature difference due to the strong variation of the thermal and transport properties of the fluid. Instead, the calculation is done using a numeric integration along the heat exchanger length. Furthermore, the model allows simulating heat exchangers at the design point and at off-design operation, what is useful in many engineering fields.

The model developed in this paper has been applied to oncethrough HRSGs and successfully validated with experimental data [8]. Furthermore, the sensitivity analysis done shows that the uncertainties in the heat exchange calculation will not lead to high inaccuracies, especially in large HRSGs.

Finally, the simulation method does not need a thorough knowledge of the geometric design of the heat exchanger. In that way, the number of input data required for the off-design simulation is remarkably small.

\section{Acknowledgements}

The authors wish to acknowledge the financial support of UNED to this work.

\section{Appendix. Order of magnitude of the convective heat- transfer coefficient of water at supercritical pressure}

In subcritical economisers and evaporators of HRSGs, the waterside convective heat-transfer coefficient may be considered as much higher than the gas-side ones. For that reason, in these subcritical exchangers expression (19) may be used (see Table 1).

This appendix shows, firstly by means of the Dittus-Boelter equation and later considering the heat-transfer deterioration, that the convective heat-transfer coefficient of supercritical liquid and vapour water (below and above of the pseudocritical point respectively) are similar to the subcritical liquid water when they flow through economisers and superheaters respectively. Consequently they are much higher than the gas-side ones.

Fig. 4 shows the convective heat-transfer coefficient of the liquid water versus the temperature taking the pressure (subcritical and supercritical) as a parameter. It was calculated by means of the Dittus-Boelter correlation applied to a tube of $30 \mathrm{~mm}$ of diameter and a velocity of $2.5 \mathrm{~m} / \mathrm{s}$ (typical values in economisers of HRSGs). The results show that the coefficient is almost independent of the

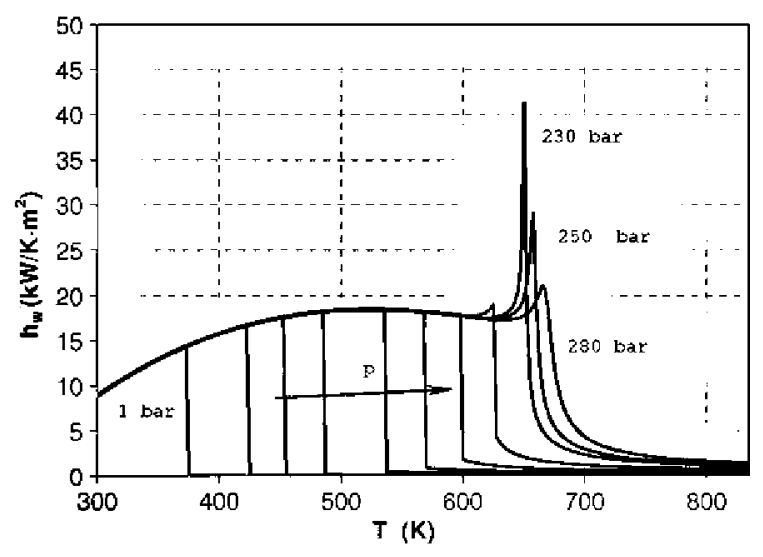

Fig. 4. Usual convective heat-transfer coefficient of liquid water.

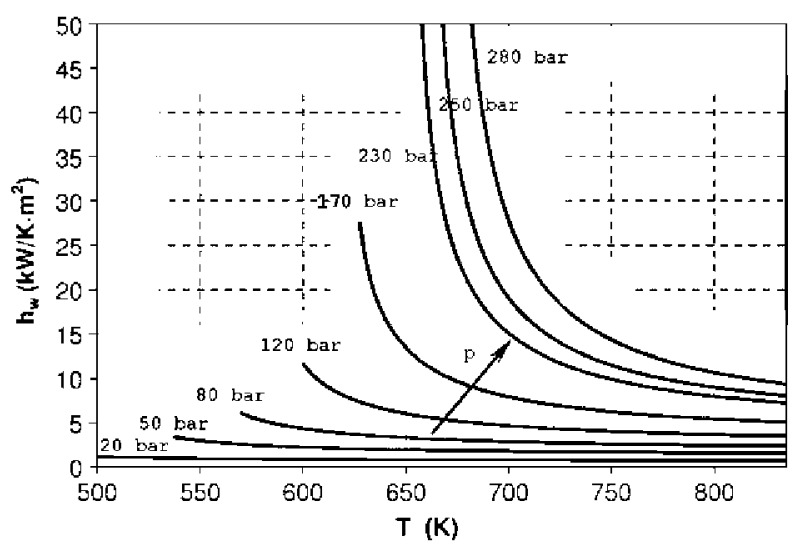

Fig. 5. Usual convective heat-transfer coefficient of steam.

pressure far from the saturation line or the pseudocritical point and that the value increases with the pressure near the pseudocritical point. The heat-transfer coefficient at the water side is always more than two orders of magnitude higher than the gas side one.

On the other hand, Fig. 5 is similar to Fig. 4 but calculating the coefficient of the steam in a tube of $30 \mathrm{~mm}$ of diameter where the velocity is $25 \mathrm{~m} / \mathrm{s}$ (typical in superheaters). In this case it can be observed that, at subcritical pressure (below of 221 bar), the value of the convective coefficient is an order of magnitude lower than the obtained before for the liquid water case (Fig. 4). However, it is also observed that the value reached at supercritical pressures is similar to the obtained for the liquid water.

Likewise, Fig. 6 shows the evolution of the convective heattransfer coefficient of the experimental HRSG used by Dechamps and Galopin [8]. The similarity between both coefficients - at liquid and vapour state - is shown again. Similar results were obtained by Dumont and Heyen [9].

Finally, as it was said in Section 2.2, at supercritical pressure the Dittus-Boelter equation is not valid to predict accurately the value of the convective heat-transfer coefficient. In order to solve this problem several corrections has been given by many authors. Cheng and Schulenberg [30] made a literature review about the matter. In their work, they show a certain lack of agreement between the different authors and point out that the corrections to the Dittus-Boelter equation differ in each particular case. Analysing the results shown in ref. [30], which do not take into account the heat-transfer deterioration phenomenon, it may be concluded that the order of magnitude of the convective heat-transfer coefficient is the same than the obtained by means of the Dittus-Boelter equation. The effect of the heat-transfer deterioration

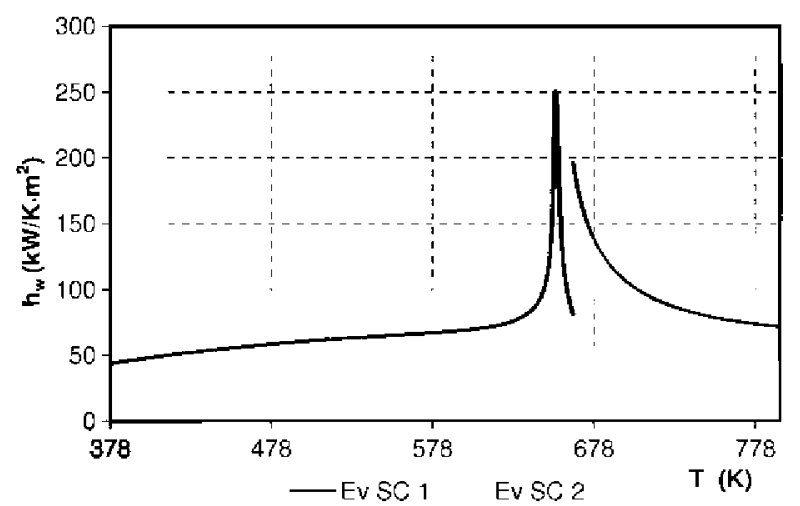

Fig. 6. Evolution of the water-side convective heat-transfer coefficient within the analysed once-through HRSG. 
could be analysed from ref. [31], where it could be observed that despite of this phenomenon, the order of magnitude of the convective heat-transfer coefficient still remains. In ref. [31] it is also discussed that the deteriorated heat transfer can be suppressed by means of flow obstructions and other heat-transfer enhancing devices. For these reasons equation (19) could be used since the gas-side heat-transfer coefficient for usual HRSG designs is much lower than the water one.

\section{References}

11 J.H. Horlock, Combined Power Plants, first ed. Pergamon Press, Oxford, 1992

[2] M. Muñoz, A. Rovira, Ingeniería Térmica. Universidad Nacional de Educación a Distancia, Madrid, 2006.

[3] R. Kehlhofer, F. Hannemann, F. Stimimann, B. Rukes, Combined-Cycle Gas \& Steam Turbine Power Plants, third ed. Pennwell, Tulsa, Oklahoma, USA 2009.

[4] A. Rovira, Desarrollo de un modelo para la caracterización termoeconómica de ciclos combinados de turbinas de gas y de vapor en condiciones de carga variable, PhD thesis. Universidad Politécnica de Madrid, Madrid, 2004.

[5] Y.S.H. Najjar, Efficient use of energy by utilizing gas turbine combined systems. Appl. Therm. Eng. 21 (2001) 407-438.

[6] Staff report, Agawam merchant GT24 combined cycle plant uses once-through HRSG. Mod. Power Syst (September 1999) 31-38.

[7] Staff report, Fast work for the Benson once-through HRSG. Mod. Power Syst. (February 2004) 23-25.

[8] P.J. Dechamps, J.F. Galopin, Once through heat recovery steam generators working with sub-and supercritical steam conditions for combined cycle. Power Gen. 3 (1997) 237-249.

[9] M.N. Dumont, G. Heyen, Mathematical modelling and design of an advanced once-through heat recovery steam generator. Comput. Chem. Eng. 28 (5) (2004) 651-660.

[10] P.J. Dechamps, Advanced combined cycle alternatives with the latest gas turbines, Trans. ASME J. Eng. Gas Turbine and Power 120 (2) (1998) 350-357.

[11] J.F. Galopin, Going supercritical: once-through is the key. Mod. Power Syst (December 1998) 39-42.

[12] J.M. Beér, High efficiency electric power generation: the environmental role Prog. Energy and Combust. Sci. 33 (2007) 107-134.

[13] M.Valdés, A. Rovira, M.D. Durán, Influence of the heat recovery steam generator design parameters on the thermoeconomic performances of combined cycle gas turbine power plants. Int. J. Energy Res. 28 (2004) 1255-1267.
[14] Staff report, Release on the IAPWS industrial formulation 1997 for the thermodynamic properties of water and steam. The International Association for the Properties of Water and Steam, 1997.

[15] M. Valdés, M.D. Durán, A. Rovira, Thermoeconomic optimization of combined cycle gas turbine using genetic algorithms. Appl. Therm. Eng. 23 (2003) 2169-2182.

[16] A.J. Chapman, Transmisión del Calor, third ed. Bellisco, Madrid, 1984.

[17] P.J. Dechamps, Incremental Cost Optimization of Heat Recovery Steam Generators. ASME COGEN-TURBO, Viena, Austria, 1995.

[18] D. Duran, A. Rovira, M. Valdes, Methodology for the thermoeconomic and design optimization of a heat recovery steam generator. In: Proc. of the 19th ECOS Int. conference, Aghia Pelagia, Greece, 2006. p. 577-86.

[19] F.W. Dittus, L.M.K. Boelte vol. 2, Univ. Calif., Berkley, Publ. Eng., 1930, 443.

[20] B.S. Petuhkov, Heat transfer and friction in turbulent pipe flow. Adv. Heat Transfer 6 (1970) 511-564.

[21] K. Yamagata, K. Nishikawa, S. Hasegawa, T. Fujii, S. Yoshida, Forced convective heat transfer to supercritical water flowing in tubes. Int. J. Heat Mass Transfer 15 (1972) 2575-2593.

[22] G. Scalabrin, L. Piazza, Analysis of forced convection heat transfer to supercritical carbon dioxide inside tubes using neural networks. Int. J. Heat Mass Transfer 46 (7) (2003) 1139-1154.

[23] D. Squarer, T. Schulenberg, D. Struwe, Y. Okab, D. Bittermann, N. Aksan, C. Maraczy, R. Kyrki-Rajamäki, A. Souyri, P. Dumazh, High performance light water reactor. Nucl. Eng. Des. 221 (2003) 167-180.

[24] X. Cheng, T. Schulenberg, D. Bitterman, P. Rau, Design analysis of core assemblies for supercritical pressure conditions. Nucl. Eng. Des. 223 (3) (2003) $279-294$.

[25] D. Shmith, Mean temperature difference in cross-flows. Engineering 138 (1934) 479.

[26] C.D. Weir, Estimating the performance of gas turbine heat-recovery boilers off-design. Proc. Inst. Mech. Eng. 202 (1988) 269-277.

[27] J.L. Rapún, Modelo matemático del comportamiento de ciclos combinados de turbinas de gas y vapor, PhD thesis. Universidad Politécnica de Madrid, Madrid, 1999.

[28] D. Duran, Estudio de Calderas de Recuperación de Calor de Ciclo Combinados de Turbinas de Gas y Vapor Empleando la Técnica de Algoritmos Genéticos, $\mathrm{PhD}$ thesis. Universidad Politécnica de Madrid, Madrid, 2004.

[29] R.K. Shah, D.P. Sekulic, Fundamentals of Heat Exchanger Design. John Wiley and Sons, Inc, Hoboken, New Jersey, 2003.

[30] X. Cheng, T. Schulenberg, Heat Transfer at Supercritical Pressures-Literature Review and Application to an HPLWR FZKA 6609. Wissenschaftliche Berichte Forschungszentrum Karlsruhe, 2001.

[31] I.L. Pioro, R.B. Duffey, Experimental heat transfer in supercritical water flowing inside channels (survey). Nucl. Eng. Des. 235 (2005) 2407-2430. 